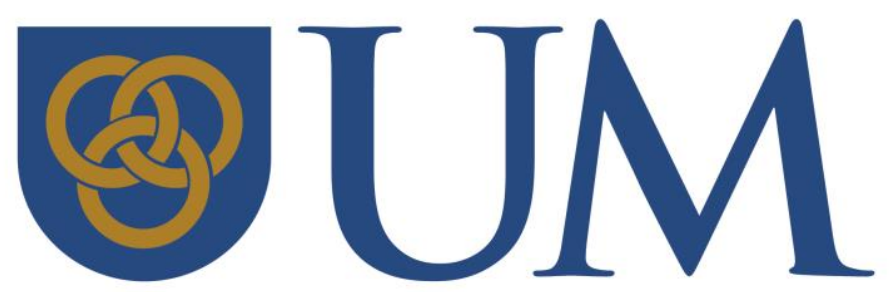

UNIVERSIDAD DE MONTEVIDEO

\author{
FACULTAD DE CIENCIAS EMPRESARIALES Y ECONOMIA
}

Serie de documentos de trabajo del Departamento de Economía /

Department of Economics Working Papers Series

\title{
Spiritual Practices and Dispositional Optimism in an Underprivileged Population
}

\author{
Gonzalo Arrieta
}

Alejandro Cid

Maria Mercedes Ponce de Leon

The working papers of the Department of Economics, Universidad de Montevideo are circulated for discussion and comment purposes. They have not been peer reviewed nor been subject to the review by the University's staff. (C) 2017 by Gonzalo Arrieta, Alejandro Cid and María Mercedes Ponce de León.

All rights reserved. Short sections of text, not to exceed two paragraphs, may be quoted without explicit permission provided that full credit, including (C) notice, is given to the source. 


\title{
Spiritual Practices and Dispositional Optimism in an Underprivileged Population
}

\author{
Gonzalo Arrieta, Alejandro Cid \& Maria Mercedes Ponce de Leon * \\ Charles E. Stokes**
}

\begin{abstract}
Optimism seems to foster the ability to manage adverse situations better - a finding especially relevant for disadvantaged populations. Employing a unique sample from a small underprivileged village, we study the association between spiritual practices and dispositional optimism. The village belongs to a developing country that is, by far, the most secular country in Latin America: this makes particularly interesting exploring the role of spiritual practices in this context. We find that spiritual practices are positively associated with higher optimism, measured by the Life Orientation Test-Revised (LOT-R): those who practice spirituality, score, on average, 14.4 percentage points higher on the LOT-R than those who do not. And this association seems to be especially robust in the case of the poor and less educated: those with spiritual practices score 20 percentage points higher on the LOT-R. Thus, the role that spiritual practices may play in dispositional optimism in disadvantaged populations deserves more attention.
\end{abstract}

Keywords: : Dispositional optimism, spiritual practices, LOT-R, hope, religion, happiness

Acknowledgments: The authors thank Rodrigo Areal, Juan Ignacio Ramirez and Juan Pablo Verdier for superb research assistance.

*Alejandro Cid (corresponding author), acid@um.edu.uy, Universidad de Montevideo, 2544 Prudencio de Pena st, Montevideo 11600, Uruguay +59827074461, Gonzalo Arrieta, garrieta@stanford.edu, Stanford University and Universidad de Montevideo, Maria Mercedes Ponce de Leon, mponcedeleon@correo.um.edu.uy, LUISS University, EIEF and Universidad de Montevideo

**Charles E. Stokes, cestokes@samford.edu, Samford University 


\section{Introduction}

Dispositional optimism is a generalized expectancy of positive future outcomes (Scheier and Carver, 1985). It plays a key role in health and motivation (Seligman, 1991), and this seems to be particularly true in underprivileged populations (Perlman, 2008). Employing a unique data set from a small disadvantaged village, we explore the role that spiritual practices may play in dispositional optimism.

The village belongs to Uruguay, a developing country that is the most secular one in LatinAmerica (Pew Survey, 2014). It is a context especially interesting to study the association between spiritual practices and outcomes like optimism and hope. According to the Pew Survey (2014), 37\% of Uruguayans state that they have no particular religion or are agnostic or atheist; whereas for the rest of the region, that number falls well below the $20 \%$ mark. Also, relatively few Uruguayans say they pray daily (29\%), whereas, all the while, for the population of its neighbor country of Brazil it is more than $60 \%$. Over the past years, this trend has become more evident, with the unaffiliated having significant net gains in Uruguay. A final result from the Pew Survey is that there is a significant gender gap with regards to the importance of religion. The share of Uruguayan women that consider religion to play an important role in their lives is about 14-15 percentage points higher than the share of men.

Within Uruguay, our focus was set on the city of Lascano, in the department of Rocha (Uruguay is divided in 19 departments), where, according to the 2011 National Census, 7645 people distributed throughout 2830 households reside. We found Lascano particularly interesting for it is a vulnerable and relatively isolated city, whose main economic activities rely on the rice industry and lacks a vibrant or growing economy. Lascano has a labor force participation rate of $54.47 \%$, which is lower than that of Rocha. As it is fairly common among underprivileged poor villages, we find that women in Lascano have a considerable harder time entering the labor market than their male counterparts, as it is evidenced by the far higher unemployment rate. With regards to education, according to the 2011 Census -the last available one-, almost half of the citizens have only managed to finish primary school. Furthermore, $3.02 \%$ of the population is illiterate, which is almost twice the number for the entire country and far greater than for the whole of Rocha (for Uruguay we find that $1.6 \%$ of population is illiterate, and in Rocha it is $2.06 \%$ ). This goes to show that people of Lascano lack promising educational opportunities, and are, all in all, far less educated than the average Uruguayan or citizen of Rocha. Also, very much associated with this, we find that the majority of the people employed have only completed primary school, which suggests that most of those who are working have low-skilled jobs with probably little chance of upward movement.

In this context of isolation, vulnerability and secularism, it is particularly interesting to study the role that spiritual practices (defined as regular praying and meditation) may play regarding dispositional optimism levels for individuals. Extensive research has proven that people who come from disadvantaged socioeconomic backgrounds are more likely to suffer from feelings of anxiety and unhappiness, but that participating in religious practices (e.g. meditation and praying) can help people cope better with the stress brought on by adversity (Maholmes, 2014). What is more, a large body of research suggests that optimism is particularly beneficial under stressful situations. Thus, studying spiritual practices and optimism among underprivileged populations becomes of the utmost interest. However, until now, much of this line of research has been focused only in developed countries.

\section{Background}

Research on dispositional optimism has consistently shown positive associations between optimism and numerous aspects of personal and professional well-being. Namely, dispositional optimism has proven to be of value for individuals suffering from a variety of mental health issues. Numerous studies have demonstrated that many desirable personal resources have a 
strong a positive association with dispositional optimism, and foster career and personal development (Salsman, Brown, Brechting, and Carlson, 2005). Furthermore, as recorded by Janice E. Perlman (2008) in her study of the favelas in Rio de Janeiro, Brazil, hope and high aspirations for the future may very well have been the mechanisms through which many families were able to overcome the obstacles they faced and leave the favela. Likewise, when studying women disadvantaged by poverty, racial minority status or both, Nancy Grote et al. (2007) found that when exposed to high levels of stress, women who are more optimistic, and thus perceived the situations they faced as more controllable, faced a much lower chance of developing clinically significant depression stemming from their socioeconomic status.

In accordance with this, Carver and Scheier (2002) show that dispositional optimism prevents depressive symptoms and fosters a sense of satisfaction after major life changes. Several authors have found dispositional optimism to be negatively related to some undesirable work issues, such as burn out and stress, and positively linked to desirable ones, such work engagement (Riolli and Savicki, 2003; Xanthopoulou et al., 2009; Barkhuizen et al., 2014). Further, individuals who expect positive outcomes have been found to have higher levels of goal attainment and goal reengagement (Rasmussen et al., 2006; Wrosch et al., 2003), as well as perseverance in the face of difficulty and when progress is slow (Carver and Scheier, 1994).

In their study, Salsman, Brown, Brechting, and Carlson (2005) found positive correlations between a set of religious- and spiritual-related variables and optimism. In addition to this, Reis and Alligood (2014) found that meditation resulted in an increase in the mean score for optimism of expecting mothers; and Brown et al. (2006), who studied the effects of Vipassana meditation (a Buddhist mindfulness-based practice) in an incarcerated population, found a significant relationship between participating in the meditation course and optimism (there was a decrease in psychiatric symptoms as well as an increase in optimism).

Given all this, scientific interest on the topic is quite understandable. Particularly so, when the focus is set on measuring dispositional optimism in fragile populations that may appear to lack positive expectations about the future, and who might find it more difficult to advance career wise.

\section{Method}

To statistically test our hypothesis that spiritual practices would be positively correlated with dispositional optimism in a vulnerable population of a deeply secular country, we (a) assess the representativeness of our sample and present a set of descriptive statistics, (b) obtain mean LOT-R scores and apply statistical tools to measure the density distribution of LOT-R scores for different sub-groups, (c) develop a correlations matrix using religion-related variables of interest and measure average optimism scores for the religion outcomes, (d) assess the statistical difference of the sub-groups of people who practice spirituality and those who do not, (e) use a multivariate regression model to estimate the differential associations of variables of interest with our dispositional optimism measure, and (f) develop additional multivariate regression models to statistically adjust these associations for differences in a set of socio-economic variables.

\subsection{Sample}

We use a survey conducted in February of 2015, in the town of Lascano (department of Rocha, Uruguay). Our sample is composed of 284 individuals over 18 years of age, each uniquely associated to his/her household (284 households represents approximately 10 percent of all households in the town).

The survey collects data on socio-demographic characteristics of the individuals, and it also includes two sections that are of particular interest for us. One consists of four religion-related 
items and the other is a unidimensional dispositional optimism section.

In Table 1 we present some evidence regarding the overall representativeness of our sample, along a number of dimensions: age, gender, employment rate, unemployment rate, retirement rate, individuals living per bedroom, poverty and educational environment. There are three main columns in the table: the first column reflects our sample of 284 households in Lascano; the second reflects a survey from a variety of similar Uruguayan cities nearby (with populations between 5.000 and 20.000 inhabitants, according to the 2011 National Census) located in the departments Rocha and Maldonado, taken from the 2014 Uruguayan Continuous Household Survey (Encuesta Continua de Hogares, ECH). The third exhibits a countrywide sample also taken from the ECH. Therefore, we compare this representative household survey run throughout the year 2015 by the National Statistical Office (INE: Instituto Nacional de Estadstica National Institute of Statistics) against our sample, both using a selection of similar cities in Rocha and Maldonado and at a national level.

We observe that individuals from households in our sample are more likely to be male (58.5 percent in our sample versus 48.6 percent of the Rocha and Maldonado sample and 47.3 of the Uruguay sample) and live in homes with less people per bedroom (1.41 versus 1.49 individuals per bedroom in Rocha and Maldonado and 1.59 for the whole country).

Our sample seems to be representative in terms of age, employment rate and retirement rate, specially comparing with similar cities. However, the unemployment rate found on our sample is more than three times larger than that found on the ECH samples.

Table 1

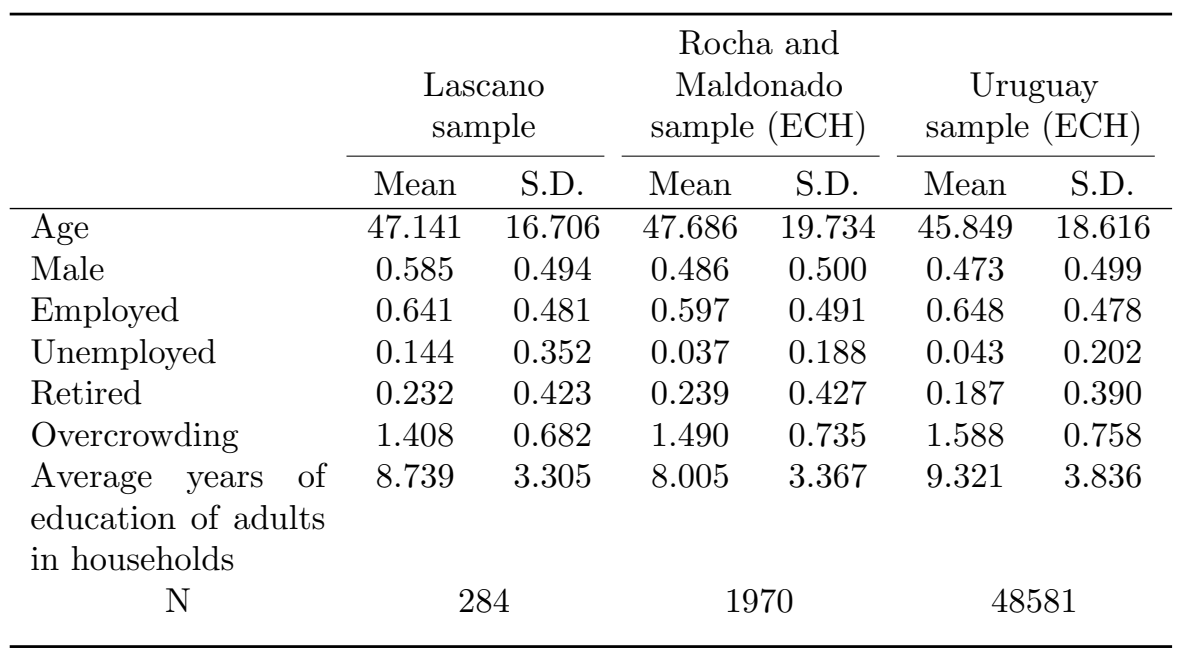

Note: ECH refers to the Continuous Household Survey (Encuesta Continua de Hogares)

\subsection{Instruments}

Dispositional optimism Dispositional optimism, as defined by Scheier and Carver (1985), is a generalized expectancy of positive future outcomes. Scheier, Carver and Bridges (1994) introduced the Life Orientation Test-Revised (LOT-R) to measure dispositional optimism. The LOT-R implies a one-dimensional conceptualization of optimism, which has been a cause of controversy and debate as several studies using empirical evidence suggest the LOT-R is bidimensional. However, three recent studies which evaluate the LOT-Rs dimensionality, demonstrate that its bi-factorial structure is an artifact of item wording, therefore supporting the unidimensionality of optimism, as it was initially introduced (Monzani, Steca, and Greco, 2014). Therefore, we measured dispositional optimism with the Spanish Version of the LOT-R which consists of 9 items. Three items are framed positively so as to assess optimism (e.g., In uncertain 
times I expect the best), three items are framed negatively in order to assess pessimism (e.g., If something can go wrong for me it will), and there are three filler items. On a 5-point Likert scale, response categories ranged from strongly disagree to strongly agree. The total LOT-R score can be calculated adding the optimism and inverted pessimism items.

Spiritual practices The survey measures God's importance in the respondent's life (scaled from 1 to 10), the individual's religious beliefs (i.e., Catholic, Christian of a different church, believer in God, agnostic/atheist, other), and how frequently he/she practices his/her religion (with three categories available: Frequently, Every now and then, Never). However, it goes beyond the standard measurement of religiosity to assess meditation, contemplation, and prayer. It constructs a spirituality measurement, assessing whether or not the individual meditates, contemplates or prays at least once a week. We focus most of our analysis on this variable under the assumption that it has an interesting association with dispositional optimism.

\subsection{Data Analysis}

We use a wide range of statistical tools to address our research questions. Having computed the mean levels of a set of variables for our sample and two other samples taken from the ECH database and determined the representativeness of our sample, we first exhibit a set of descriptive statistics. Second, we develop a graph showing the means of the different outcomes of four variables of interest. Third, we construct a scatter plot to show LOT-R score distribution among different ages. We conduct a histogram analysis to assess the density distribution of the scores for the sub-groups of people who practice spirituality and those who do not. Forth, we develop a correlations matrix using the religion-related variables of interest and measure average optimism scores for the four possible religion-outcomes. We then assess the statistical difference of the sub-groups of people who practice spirituality and those who do not, calculating difference-in-means tests. To estimate the differential associations of the variables of interest with our dispositional optimism measure, we use a baseline ordinary least squares regression model. We estimate three ordinary least square (OLS) regression equations. Model 1 is the baseline equation and include the variable indicating whether or not the individual has a religion and control variables. Model 2 maintains the previous regressors and adds a variable addressing the frequency in which religious individuals practice their religion. Model 3 finally adds the spiritual practices variable to the regressors. The equation for this model is:

$$
\begin{aligned}
& \text { LOT- }_{i}=\alpha+\beta_{1} \text { Hasreligion }_{i}+\beta_{2} \text { Frequency }_{i}+\beta_{3} \text { Prspirituality }_{i}+\delta \text { Controls }_{i}+\epsilon_{i} \text { for } \\
& (i=1, \ldots, n: n>p)
\end{aligned}
$$

with $\mathrm{n}$ being the number of observations in the dataset, and $\mathrm{p}$ the number of estimates parameters. Where LOT-R is the individual's dispositional optimism score, measured by the Life Orientation Test-Revised, $\alpha$ is shared intercept, $\beta_{1}$ is the coefficient for the variable measuring whether or not the individual has a religion, Hasreligion corresponds to this variable, $\beta_{2}$ is the coefficient for the frequency in which individuals practice their religion, Frequency corresponds to this variable, $\beta_{3}$ is the coefficient for the practices spirituality variable, Prspirituality corresponds to this variable, $\delta$ is the vector of coefficients for control variables and Control corresponds to the control variables. $\epsilon$ is an independent and identically distributed random error term. Finally, we then develop additional regression models to statistically adjust these associations for differences in a set of socio-economic variables (i.e. gender, age, health, wealth and education). 


\section{Summary statistics}

In Table 2 we define some of the variables used in the analysis and present a set of descriptive statistics of these variables. We have a sample of 284 individuals aged 18-89 that live in Lascano with a mean age of 47 . Moreover, at $58.5 \%$, men made up the bulk of our sample. We can also see that, on average, individuals have lived in Lascano for most of their lives, rate God's importance at 7.1 (from a scale of 1 to 10), and have a self-reported state of health of 7.9 (from a scale of 1 to 10 ). Interestingly, $21 \%$ of the respondents are atheists or agnostics, and only $18.75 \%$ of those who have a religion affiliation frequently practice it $(14.8 \%$ for the whole sample, including atheists and agnostics). The average optimism score is 17.1 points, slightly above the scores found on relevant literature. ${ }^{1}$

\footnotetext{
${ }^{1}$ Salsman, Brown, Brechting, and Carlson, (2005) found a mean score of 16; in Glaesmer et al. (2012), the mean value was 15.2; and Scheier, Carver and Bridges (1994) found an average score of 14.3 using a sample of college students.
} 
Table 2: Definition and Description of Variables

\begin{tabular}{|c|c|c|c|c|c|}
\hline & Description of variables & Mean & S.D. & Min. & Max. \\
\hline Age & Age of the respondent in years & 47.141 & 16.706 & 18 & 89 \\
\hline Male & $=1$ if the individual is male & 0.585 & 0.494 & 0 & 1 \\
\hline Years living in Lascano & $\mathrm{N}^{o}$ of years living in Lascano & 37.872 & 19.498 & 0.25 & 89.00 \\
\hline $\begin{array}{l}\text { Average years of } \\
\text { education of adults in } \\
\text { households }\end{array}$ & $\begin{array}{l}\text { Average } \mathrm{n}^{\circ} \text { of years of education for all } \\
\text { individuals over } 18 \text { years old living in } \\
\text { the household }\end{array}$ & 8.739 & 3.305 & 0 & 20 \\
\hline Overcrowding & $\begin{array}{l}\text { Number of people per bedroom living } \\
\text { in the household }\end{array}$ & 1.408 & 0.682 & 0.33 & 6.00 \\
\hline $\begin{array}{l}\text { Importance of God in } \\
\text { life }\end{array}$ & $\begin{array}{l}\text { Subjects rated the importance of God } \\
\text { in their lives (with } 10 \text { being the highest } \\
\text { importance) }\end{array}$ & 7.095 & 3.572 & 1 & 10 \\
\hline Job satisfaction & $\begin{array}{l}\text { Subjects rate their job satisfaction ( } 1 \\
\text { being very unsatisfied and } 10 \text { being very } \\
\text { satisfied) }\end{array}$ & 8.060 & 1.924 & 1 & 10 \\
\hline Health & $\begin{array}{l}\text { Self-reported state of health ( } 1 \text { being } \\
\text { very bad health and } 10 \text { being excellent } \\
\text { health) }\end{array}$ & 7.891 & 2.074 & 1 & 10 \\
\hline Family Stability Index & $\begin{array}{l}\text { Equals the sum of two items, each on a } \\
\text { 4-point Likert scale }\end{array}$ & 6.925 & 1.411 & 2 & 8 \\
\hline Unemployed & $=1$ if subject is unemployed & 0.144 & 0.352 & 0 & 1 \\
\hline Poverty index & Poverty index & 0.357 & 0.233 & 0 & 1 \\
\hline Has a religion & $\begin{array}{l}=1 \text { if the respondent is not an atheist } \\
\text { or agnostic }\end{array}$ & 0.789 & 0.409 & 0 & 1 \\
\hline $\begin{array}{l}\text { Always practices } \\
\text { his/her religion }\end{array}$ & $\begin{array}{l}=1 \text { if subject claims to always practice } \\
\text { his/her religion }\end{array}$ & 0.148 & 0.356 & 0 & 1 \\
\hline Optimism Sub-scale & $\begin{array}{l}\text { Sum of } 3 \text { items, each on a } 5 \text {-point Likert } \\
\text { scale. Response categories ranged from } \\
\text { strongly disagree to strongly agree }\end{array}$ & 9.742 & 2.640 & 0 & 12 \\
\hline Pessimism Sub-scale & $\begin{array}{l}\text { Sum of } 3 \text { items, each on a } 5 \text {-point Likert } \\
\text { scale. Response categories ranged from } \\
\text { strongly disagree to strongly agree }\end{array}$ & 4.673 & 3.015 & 0 & 12 \\
\hline LOT-R Score & $\begin{array}{l}\text { Sum of the optimism and inverted } \\
\text { pessimism score }\end{array}$ & 17.071 & 4.527 & 0 & 24 \\
\hline Observations & & \multicolumn{4}{|c|}{284} \\
\hline
\end{tabular}

Note: The Family Stability Index is the sum of 2 items, each of which is a sentence from which subject can agree or disagree on a scale of 1 to 4 . The number 4 corresponded to strongly agree and the Index varies from 2 to 8 . A translation of these items is: "The best environment for children to grow is a home where the father and mother are present"; and "For parents, the homes affective stability should be more important than attending their personal projects". The poverty index is created as follows: 11 dummy variables indicate if the household has each of the following: fridge, washing machine, Internet connection, A/C, hot water, dishwasher, T.V., freezer, car, heater, and computer. The index results of calculating the following for each observation: index $11=\sum\left(\right.$ Variable $\left.* \frac{\alpha}{\gamma}\right)$ where $\alpha$ is 1 minus the average value of each of the dummy variables previously stated considering all observations, and $\gamma$ is the sum of the $11 \alpha s$. Variable is each of the dummy variables of interest and we sum across all 11 dummy variables. Each of the pessimism and optimism items takes values from 0 to 4, 0 being strongly disagree and 4 being strongly agree. For more information on the LOT-R refer to Scheier, Carver and Bridges (1994). The translation process and information on the comparability of the translated instruments for the LOT-R are reported in Perczek, Carver, Price and Pozo-Kaderman (2000). 
For further description and understanding of our samples characteristics, in figure 1 we show the mean of the LOT-R score for the outcomes of a set of four variables. Only respondents whose self-reported state of health is higher than 7 scored above the mean LOT-R score. Looking at the age pattern we conclude that the youngest and eldest subjects in our sample appear to be the least optimistic, while young adult respondents in their 30s and 40s are the most optimistic. Subjects who practice their religion more often happen to be more optimistic. According to employment condition, only subjects who had a job at the time of the survey scored above the mean LOT-R score of 17.1.

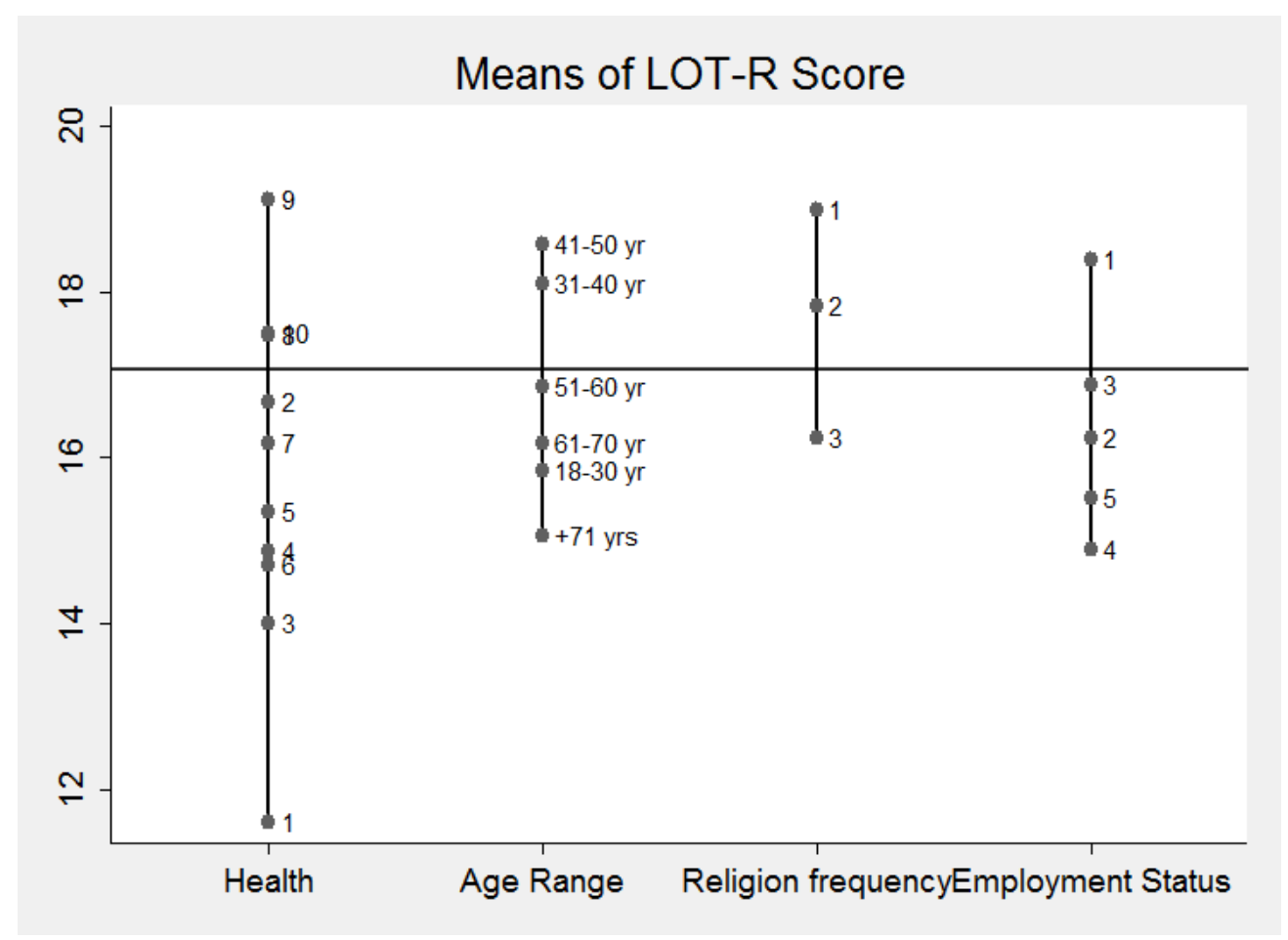

Fig. 1 LOT-R scores by health, age, frecuency with which the person practices his/her religion and employment status

Note: the categories of employment status are: $1=$ employed, $2=$ unemployed, $3=$ underemployed, $4=$ inactive and $5=$ retired

\subsection{Religion-related variables}

In table 3 we documented the correlations between the three religion-related variables of interest. As expected, all three correlations are positive and distinguishable from zero. 
Table 3: Correlations of religious variables of interest

\begin{tabular}{lccc}
\hline & $\begin{array}{c}\text { Meditates at } \\
\text { least once a } \\
\text { week }\end{array}$ & $\begin{array}{c}\text { Always practices } \\
\text { his/her religion }\end{array}$ & $\begin{array}{c}\text { Has a } \\
\text { religion }\end{array}$ \\
\hline $\begin{array}{l}\text { Meditates at least once a } \\
\text { week }\end{array}$ & 1 & & \\
$\begin{array}{l}\text { Always practices his/her } \\
\text { religion }\end{array}$ & $0.391^{* * *}$ & 1 & 1 \\
$\begin{array}{l}\text { Has a religion } \\
{ }^{* * *} p<0.01 ;^{* *} p<0.05 ;^{*} p<0.1\end{array}$ & $0.490^{* * *}$ & & \\
\hline
\end{tabular}

We will have a closer look at these three religion-related variables throughout the paper, specially focusing on the spiritual practices variable. Particularly, we now consider the respondent's stated religion. Figure 2 presents the LOT-R average score for the four possible religion affiliations. Looking at the confidence intervals, we conclude that although mean values of dispositional optimism differ between the four outcomes, we cannot reject the possibility that these four are equal.

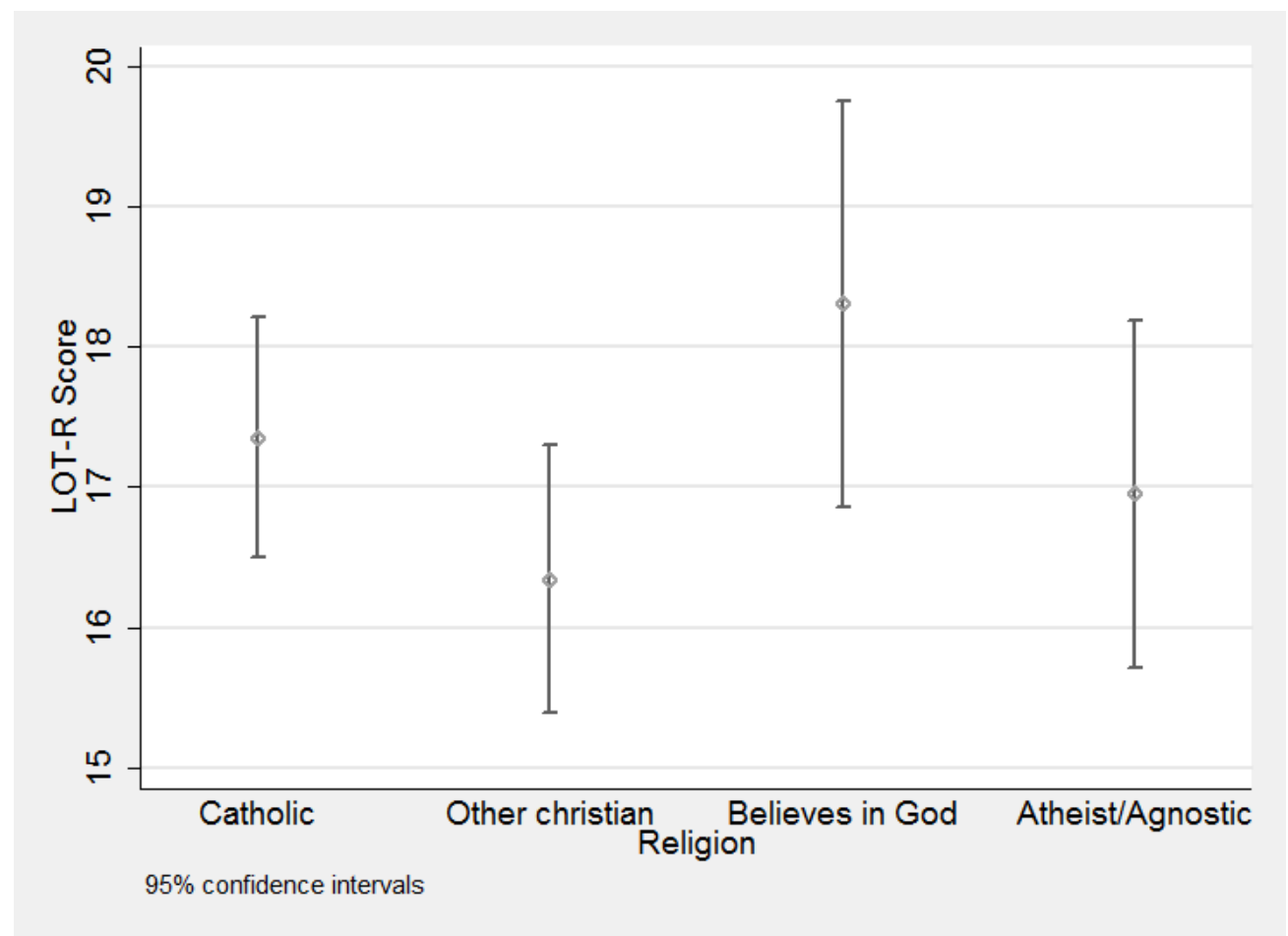

Fig. 2: LOT-R scores for 4 religion affiliations

\subsection{Age and dispositional optimism}

In figure 3 and 4 we report separate graphs with scatterplots of LOT-R scores and age. In figure 3 we look only at subjects who practice spirituality while on figure 4 we look only at those who do not. Interestingly, we find that age makes no significant difference on dispositional optimism for subjects who practice spirituality. In contrast, for individuals who do not, we find that LOT-R scores diminish as age increases, and this reduction is statistically significant. Interestingly, this is actually contrary to what was found by Eppler et al. (2000) and Ai et al. (2002) who concluded that optimism was increasing with age. However, this is likely due to the fact that in neither of these studies were they analyzing such relationships in underprivileged populations. Therefore, this could be a reflection of the uniqueness of our study and sample. 


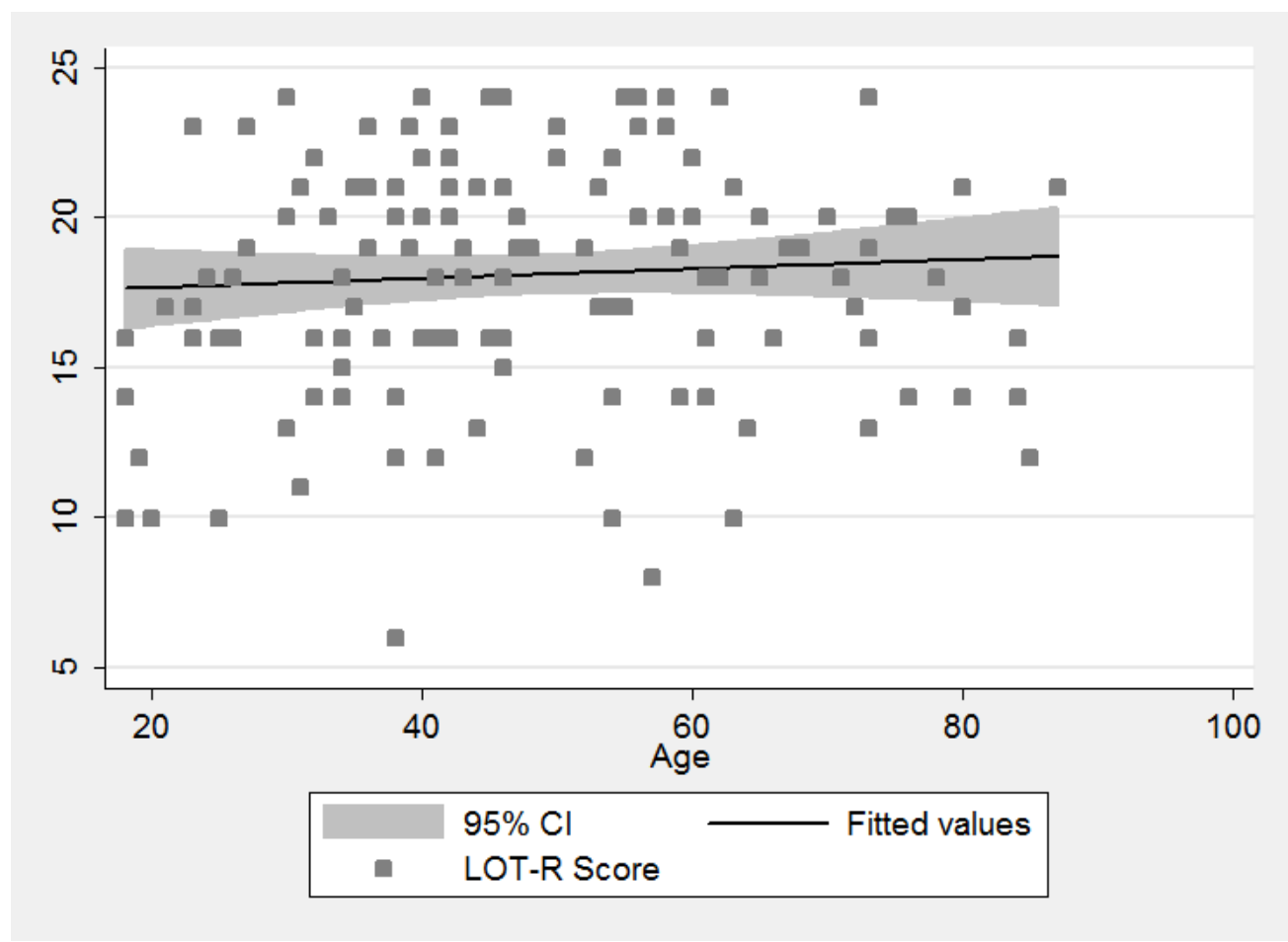

Fig. 3: Scatterplot of LOT-R and age for those who practice spirituality

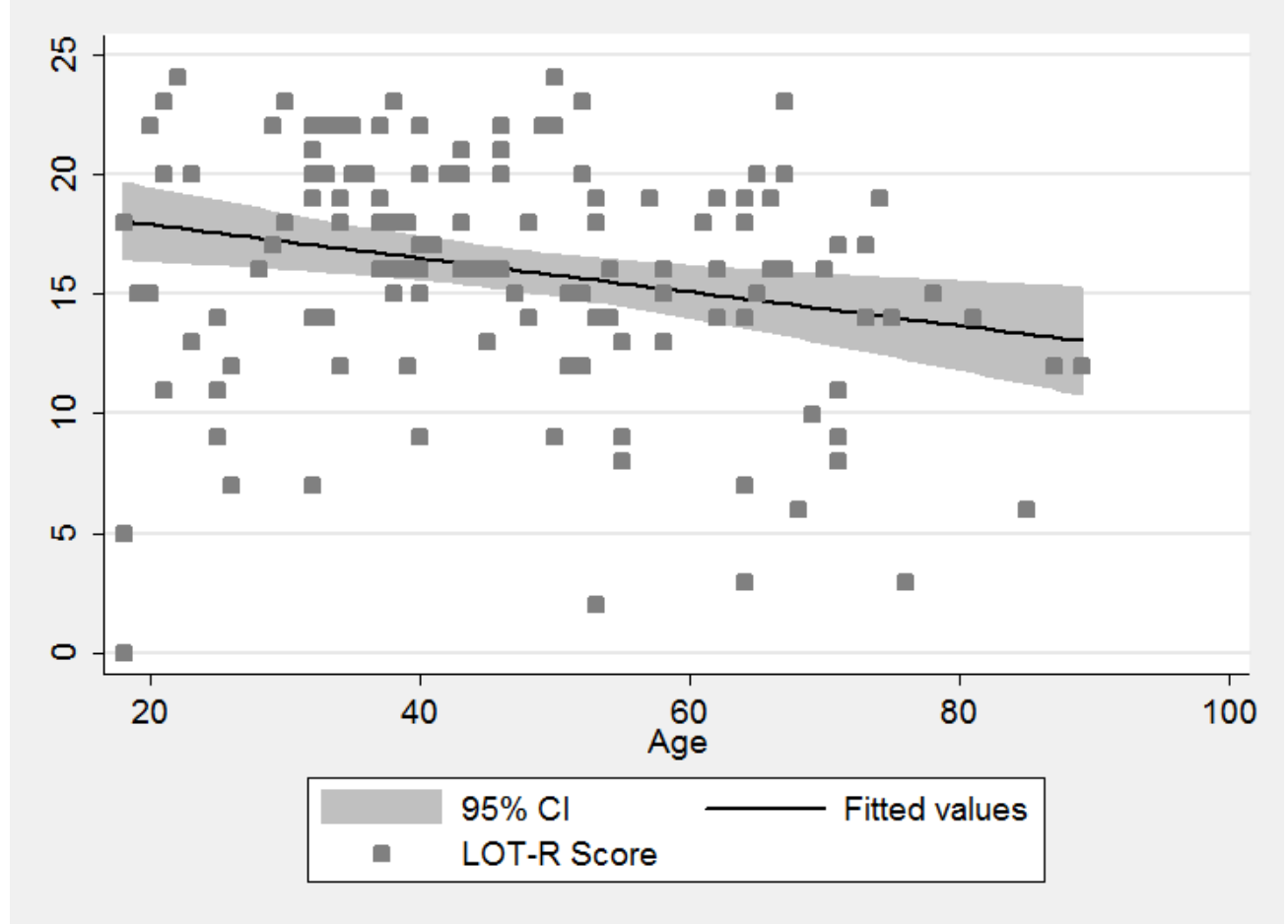

Fig. 4: Scatterplot of LOT-R and age for those who do not practice spirituality

\subsection{Differences by gender and spiritual practice}

In tables $4 \mathrm{~A}$ and $4 \mathrm{~B}$ we show means and standard deviations for a set of variables of interest, differentiating by individuals who practice spirituality and those who do not. On the last column to the right, difference-in-mean tests are shown for these two groups. As seen in table $4 \mathrm{~A}$, we find statistically significant differences on average age of men who practice spirituality 
compared to those who do not at the $10 \%$ level: men who practice spirituality are on average 4.24 years younger. Further, in table 4B we see that for females we find a significant difference as well, by which women who practice spirituality are, on average, 8.42 years older than those who do not. No significant differences arose from this statistical analysis on the self-reported health variable between the two sub-groups, for either gender. The Family Stability Index shows higher scores for individuals who practice spirituality for both, males and females. As expected, both men and women show significant differences in the level of Gods importance in their lives, percentage of individuals who believe in a God and percentage of individuals who frequently practice their religion, between those who practice spirituality and those who do not. In fact, as one might expect, those who practice spirituality are more than $35 \%$ (35\% for men and $42 \%$ for women) more likely to have a religion than those who do not. Once again, from tables $4 \mathrm{~A}$ and $4 \mathrm{~B}$ we also observe that men and women who practice spirituality show over $10 \%$ higher levels of dispositional optimism than those who do not (measured by the overall LOT-R score). If we consider the optimism and pessimism sub-scales, men who do not practice spirituality show higher levels of pessimism than their meditating or praying counterparts, but no such statistically significant difference is found for women. Spiritual practice is associated with significantly higher levels of the optimism sub-scale for both genders.

Table 4 A: Mean differences by spiritual practice for males

\begin{tabular}{|c|c|c|c|c|c|}
\hline \multirow[b]{3}{*}{ Variable } & \multicolumn{5}{|c|}{ Males } \\
\hline & \multicolumn{2}{|c|}{ Does not Practice Spirituality } & \multicolumn{2}{|c|}{ Practices Spirituality } & \multirow[b]{2}{*}{ Mean Diff. } \\
\hline & Mean & S.D. & Mean & S.D. & \\
\hline Age & 48.737 & 15.420 & 44.493 & 14.930 & $-4.244^{*}$ \\
\hline Years living in Lascano & 41.500 & 16.754 & 34.507 & 18.286 & $-6.993^{* *}$ \\
\hline $\begin{array}{l}\text { Average years of } \\
\text { education of adults in } \\
\text { households }\end{array}$ & 8.400 & 3.546 & 9.361 & 3.283 & $0.961^{*}$ \\
\hline Overcrowding & 1.468 & 0.779 & 1.495 & 0.743 & 0.0276 \\
\hline $\begin{array}{l}\text { Importance of God in } \\
\text { life }\end{array}$ & 5.263 & 3.627 & 9.253 & 1.701 & $3.991^{* * *}$ \\
\hline Job satisfaction & 7.925 & 2.110 & 8.427 & 1.637 & 0.502 \\
\hline Health & 7.763 & 2.148 & 8.240 & 1.822 & 0.477 \\
\hline Family Stability Index & 7.000 & 1.206 & 7.446 & 1.009 & $0.446^{* *}$ \\
\hline Unemployed & 0.163 & 0.371 & 0.107 & 0.311 & -0.0558 \\
\hline Poverty index & 0.347 & 0.240 & 0.353 & 0.232 & 0.0358 \\
\hline Has a religion & 0.637 & 0.484 & 0.987 & 0.115 & $0.349^{* * *}$ \\
\hline $\begin{array}{l}\text { Always practices } \\
\text { his/her religion }\end{array}$ & 0.000 & 0.000 & 0.293 & 0.458 & $0.293^{* * *}$ \\
\hline Optimism Sub-scale & 9.325 & 3.060 & 10.365 & 2.143 & $1.040^{* *}$ \\
\hline Pessimism Sub-scale & 5.237 & 3.139 & 3.973 & 2.736 & $-1.264^{* *}$ \\
\hline LOT-R Score & 16.087 & 4.726 & 18.405 & 3.850 & $2.318^{* * *}$ \\
\hline Observations & & 30 & & 5 & 155 \\
\hline
\end{tabular}


Table 4 B: Mean differences by spiritual practice for females

\begin{tabular}{|c|c|c|c|c|c|}
\hline \multirow[b]{3}{*}{ Variable } & \multicolumn{5}{|c|}{ Females } \\
\hline & \multicolumn{2}{|c|}{ Does not Practice Spirituality } & \multicolumn{2}{|c|}{ Practices Spirituality } & \multirow[b]{2}{*}{ Mean Diff. } \\
\hline & Mean & S.D. & Mean & S.D. & \\
\hline Age & 44.292 & 18.850 & 52.710 & 17.383 & $8.418^{* *}$ \\
\hline Years living in Lascano & 36.750 & 22.324 & 39.973 & 21.024 & -3.223 \\
\hline $\begin{array}{l}\text { Average years of } \\
\text { education of adults in } \\
\text { households }\end{array}$ & 8.493 & 3.134 & 8.453 & 3.177 & 0.0397 \\
\hline Overcrowding & 1.326 & 0.564 & 1.302 & 0.621 & 0.0233 \\
\hline $\begin{array}{l}\text { Importance of God in } \\
\text { life }\end{array}$ & 4.521 & 3.591 & 9.242 & 1.575 & $4.721^{* * *}$ \\
\hline Job satisfaction & 7.958 & 1.584 & 7.903 & 2.070 & 0.0551 \\
\hline Health & 7.521 & 2.250 & 7.742 & 2.311 & -0.221 \\
\hline Family Stability Index & 5.979 & 1.874 & 6.839 & 1.369 & $0.860^{* * *}$ \\
\hline Unemployed & 0.146 & 0.357 & 0.194 & 0.398 & 0.0477 \\
\hline Poverty index & 0.387 & 0.226 & 0.301 & 0.238 & $0.0862^{*}$ \\
\hline Has a religion & 0.563 & 0.501 & 0.984 & 0.127 & $0.421^{* * *}$ \\
\hline $\begin{array}{l}\text { Always practices } \\
\text { his/her religion }\end{array}$ & 0.021 & 0.144 & 0.210 & 0.410 & $0.189^{* * *}$ \\
\hline Optimism Sub-scale & 8.787 & 2.970 & 10.016 & 2.214 & $1.183^{* *}$ \\
\hline Pessimism Sub-scale & 5.188 & 3.167 & 4.581 & 2.866 & 0.607 \\
\hline LOT-R Score & 15.681 & 5.486 & 17.435 & 3.700 & $1.790^{* *}$ \\
\hline Observations & & & & & 110 \\
\hline
\end{tabular}

${ }^{* * *} p<0.01 ;{ }^{* *} p<0.05 ;^{*} p<0.1$ 
Figure 5 illustrates four histograms showing density distribution of LOT-R scores divided by gender and practice spirituality groups. As expected, and in line with previous findings, the histogram confirms that subjects who practice spirituality show higher levels of dispositional optimism. Remarkably, the effect is stronger for women at the lower end of the scale and for men at the higher end. In this sense, we see that the tail at the left- end of the histogram accumulates a relatively large proportion of density for women who do not practice spirituality, yet no tail on the left end of the histogram is found for women who do. For men, we can still see a tail at the left end even when considering only those who practice spirituality. Nevertheless, this group shows a much larger accumulation of density on the right-end of the histogram.

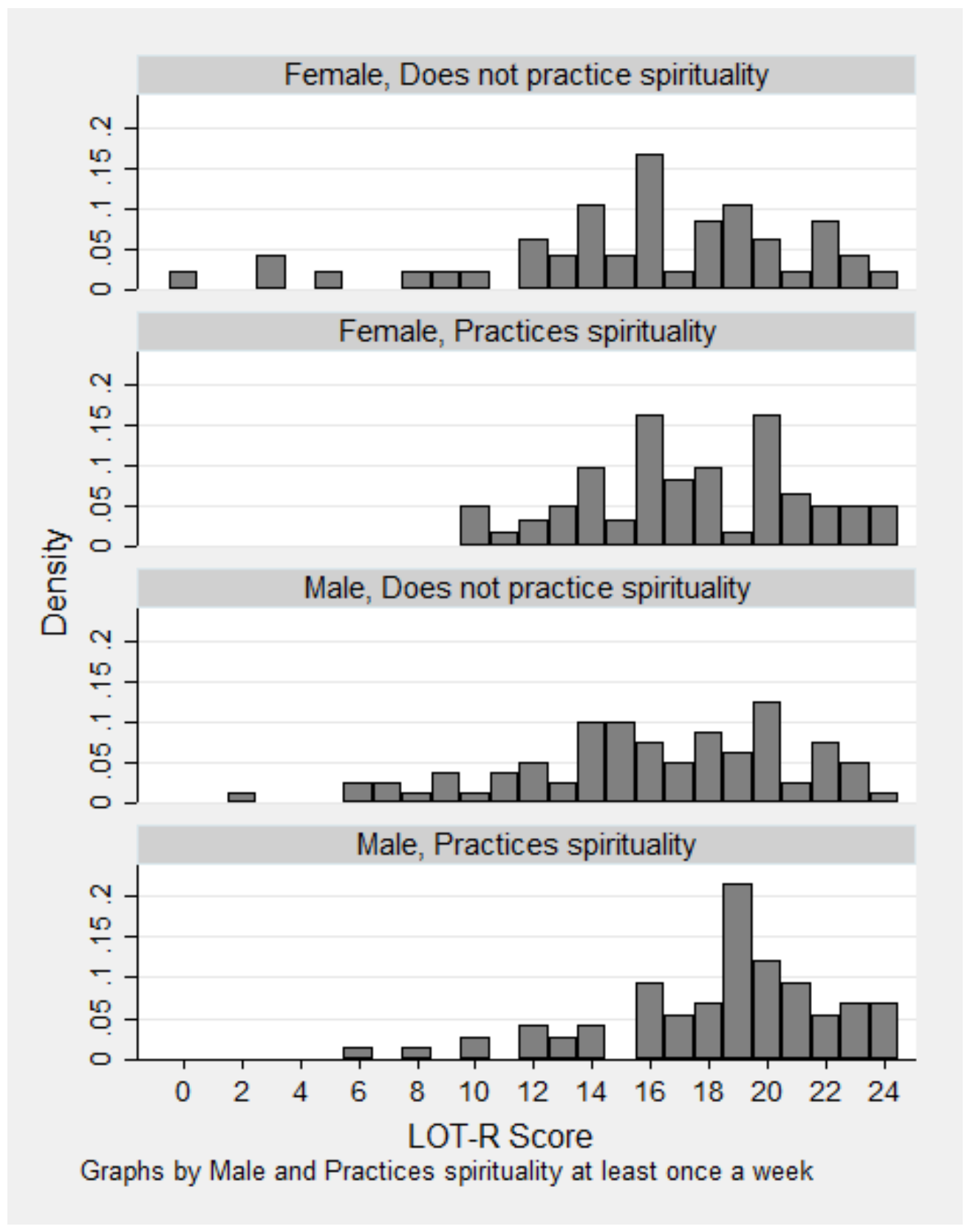

Fig. 5: Histograms of LOT-R scores divided by gender and practice spirituality groups 


\section{$5 \quad$ Results}

In this section we present the finding of our multi-variate regression analyses in two tables. In table 5 we report the statistical relationship between LOT-R scores and the three religion-related variables of interest adjusted for a set of socio-economic variables (columns (1), (2) and (3)). Column (1) refers to the baseline regression in which we look at the effect of having a religion and find no effect given the set of control variables considered. The regression equation in column (2) added the variable measuring if the individual frequently practices his/her religion. In this case, we find a significant positive coefficient which tells us that frequently practicing a religion is associated with 1.35 more points on the LOT-R score, given the control variables considered. Nonetheless, this effect loses significance when the spiritual practices variable comes into play (column (3)). One interpretation for this finding is that the whole effect of the religion-related variables is associated with the practicing spirituality effect. According to the three models on table 5, the educational environment of the household is strongly associated with high dispositional optimism levels. This effect is only slightly diminished as new religion-related variables were included, but still remained significantly different from zero.

Table 5: The impact of religion-related variables on LOT-R score

\begin{tabular}{lccc}
\hline & $(1)$ & $(2)$ & $(3)$ \\
& LOT-R & LOT-R & LOT-R \\
Variable & Score & Score & Score \\
\hline Age & -0.010 & -0.012 & -0.007 \\
& $(0.020)$ & $(0.020)$ & $(0.019)$ \\
Male & 0.425 & 0.410 & 0.649 \\
& $(0.576)$ & $(0.578)$ & $(0.567)$ \\
Subject mas born in Lascano & 0.110 & 0.107 & 0.346 \\
& $(0.577)$ & $(0.574)$ & $(0.556)$ \\
Poverty index & 0.957 & 0.902 & 1.487 \\
& $(1.772)$ & $(1.749)$ & $(1.673)$ \\
Average years of education of adults in & & & \\
households & $0.306^{* *}$ & $0.283^{* *}$ & $0.250^{*}$ \\
& $(0.141)$ & $(0.143)$ & $(0.134)$ \\
Has a religion & 0.086 & -0.137 & $-1.508^{*}$ \\
& $(0.682)$ & $(0.702)$ & $(0.801)$ \\
Always practices his/her religion & & $1.350^{* *}$ & 0.281 \\
& & $(0.659)$ & $(0.650)$ \\
Practices Spirituality at least once a week & & & $2.596^{* * *}$ \\
Constant & & & $(0.671)$ \\
& $14.092^{* * *}$ & $14.389^{* * *}$ & $13.861^{* * *}$ \\
Observations & $(1.739)$ & $(1.770)$ & $(1.677)$ \\
R-squared & 263 & 263 & 263 \\
Adjusted R-squared & 0.077 & 0.086 & 0.142 \\
\hline
\end{tabular}

Robust standard errors in parentheses

${ }^{* * *} p<0.01 ;{ }^{* *} p<0.05 ;{ }^{*} p<0.1$

Note: OLS regression

Next, we investigate whether, and to what extent, there are differential effects of spiritual practice on dispositional optimism for different groups of individuals. In table 6 we present separate results of LOT-R scores for men and women (columns (1) and (2)), different age intervals (columns (3), (4), (5) and (6)), individuals of bad-, regular- and good-health condition (self-reported; columns (7), (8) and (9)), poor, intermediate and richer subjects (columns (10), (11) and (12)) and four different educational levels (columns (13), (14), (15) and (16)).

We find that practicing spirituality has a significant association for both genders, (2.1 
points higher for men and 2.7 for women, on the LOT-R scale from 0 to 24 ). The spiritual practice coefficient is not statistically significant for subjects younger than 50, but it grows to be significant and strongly positive as age increases. This suggests that the association between practicing spirituality and dispositional optimism is present and strong for elder individuals but is non-existent for other adults. Subjects older than 50 who practice spirituality are expected to score more than 4 points higher on the LOT-R than those who do not. For every category of health status, practicing spirituality has a positive and significant association with dispositional optimism.

This finding seems to show the particular importance that spiritual practice may have in an underprivileged subpopulation, as it was hypothesized at the very beginning of this research. The effects considering different educational levels show that practicing spirituality is not associated with higher dispositional optimism neither for low-educated individuals nor for the more highly educated ones. However, for the two intermediate educational levels (i.e. those whose highest academic achievement was to finish elementary school or middle school), individuals who do practice spirituality score more than 3 points higher on the LOT-R scale. Finally, and interestingly, while for the poor and middle class the effect is important, for the richest individuals of our sample, no significant effect is found.

All in all, Table 6 shows that in most subpopulations (defined by sociodemographic categories), the association between spiritual practices - prayer and meditation - and dispositional optimism -measured by the LOT-R - is positive and significantly different from zero, and ranges from 1.62 to 4.78 points. Since the average optimism LOT-R score is 17.1 for all the sample, spiritual practice increases the LOT-R score in at least 9.5 percent, and could even achieve a 28 percent increase in some subpopulations. Interestingly, in no sub-population do we find a significant negative association between spiritual practice and dispositional optimism. 


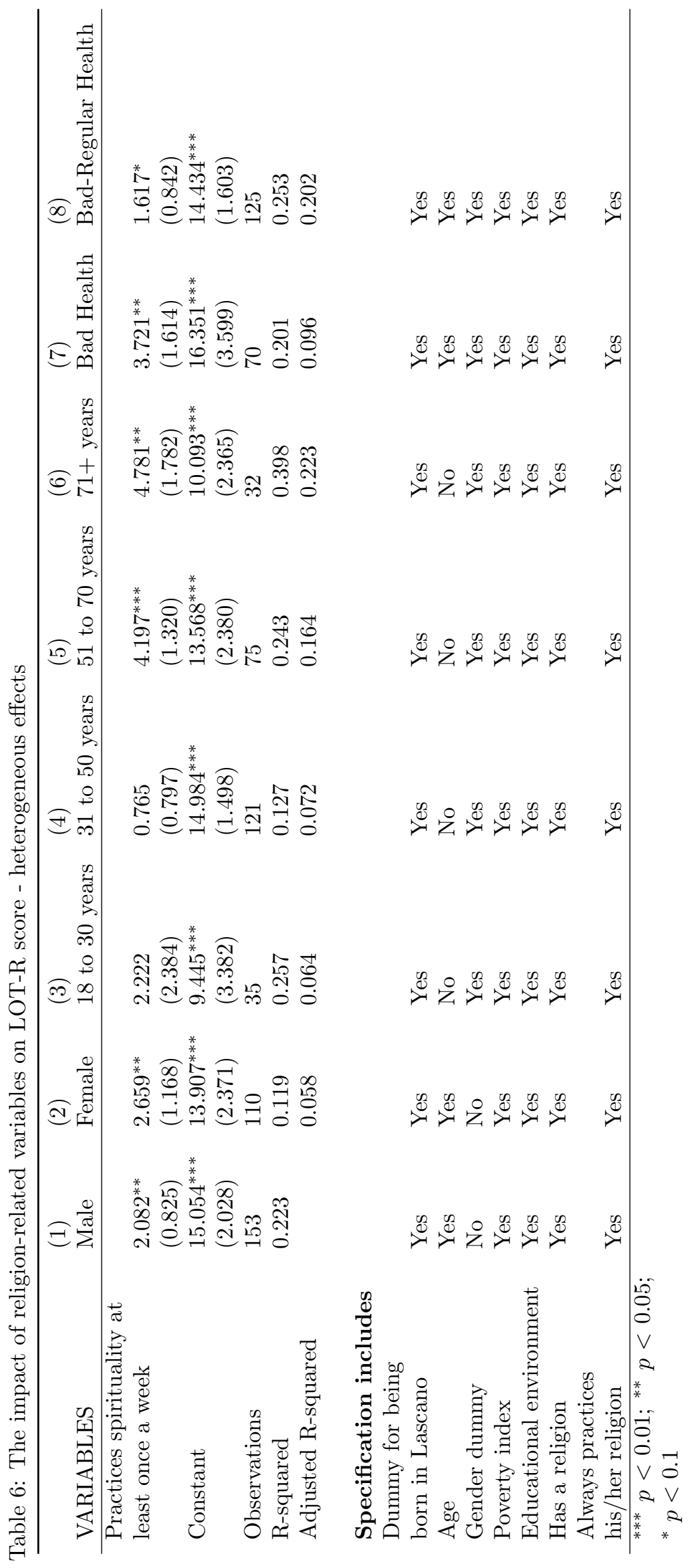




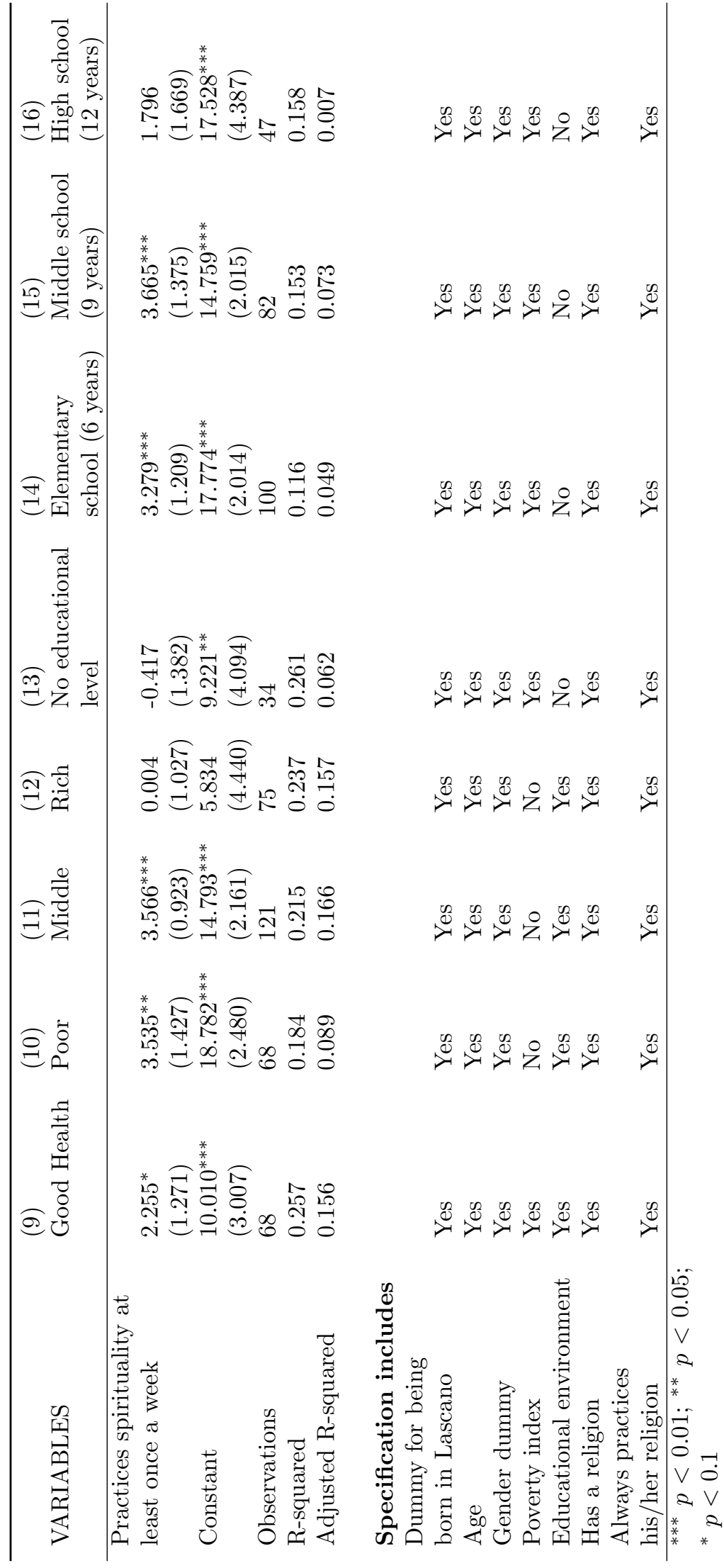




\section{Conclusion}

Our results suggest the existence of a strong and positive association between practicing spirituality weekly and dispositional optimism. This finding could be paramount, due to the fact that we study such relationship in a special environment where hope and optimism seem to be of the utmost importance. Those respondents who practice spirituality, scored, on average, 14.4 percentage points higher on the LOT-R than those who do not. This association is significant even when controlling for socioeconomic and religious variables, as the multivariate regressions show.

The heterogeneous effects strategy helped conclude that the association is particularly strong for adults over 50 years of age, as well as for individuals with very bad health or less education. Our findings contribute to previous literature helping to focus research on the eventual role of spiritual practices - prayer and meditation - on dispositional optimism, to cultivate hope in a deeply underprivileged environment, even in the most secular country.

Beliefs about the future have recently been empirically linked with resilience (SulimaniAidan, 2016). But little attention has been paid to the role of spiritual practices on future expectations in vulnerable settings. The focus of our research on praying \& meditation and Dispositional Optimism - i.e. the generalized expectancy of positive future outcomes- aims to address that issue. Connecting spiritual practices with resilience, within deeply disadvantaged populations, deserves more research.

\section{Funding}

Not applicable.

\section{Disclosure}

The authors declare that there is no conflict of interest.

\section{Ethical approval}

All the research was performed following ethical standards. 


\section{References}

[1] Ai, A. L., Peterson, C., Bolling, S. F., and Koenig, H. (2002). Private prayer and optimism in middle-aged and older patients awaiting cardiac surgery. The Gerontologist, 42(1), 70-81.

[2] Barkhuizen, N., Rothmann, S., and Vijver, F. J. (2014). Burnout and work engagement of academics in higher education institutions: Effects of dispositional optimism. Stress and Health, 30(4), 322-332.

[3] Bowen, S., Witkiewitz, K., Dillworth, T. M., Chawla, N., Simpson, T. L., Ostafin, B. D., ... and Marlatt, G. A. (2006). Mindfulness meditation and substance use in an incarcerated population. Psychology of addictive behaviors, 20(3), 343.

[4] Brissette, I., Scheier, M. F., and Carver, C. S. (2002). The role of optimism in social network development, coping, and psychological adjustment during a life transition. Journal of personality and social psychology, 82(1), 102.

[5] Eppler, M. A., Carsen-Plentl, C., and Harju, B. L. (2000). Achievement goals, failure attributions, and academic performance in nontraditional and traditional college students. Journal of Social Behavior and Personality, 15(3), 353.

[6] Glaesmer, H., Rief, W., Martin, A., Mewes, R., Brhler, E., Zenger, M., and Hinz, A. (2012). Psychometric properties and populationbased norms of the Life Orientation Test Revised (LOTR). British journal of health psychology, 17(2), 432-445.

[7] Grote, N. K., Bledsoe, S. E., Larkin, J., Lemay, E. P., and Brown, C. (2007). Stress exposure and depression in disadvantaged women: The protective effects of optimism and perceived control. Social Work Research, 31(1), 19-33.

[8] Holt, J. (2000). Exploration of the concept of hope in the Dominican Republic. Journal of Advanced Nursing, 32(5), 1116-1125.

[9] Hornby, G., and Seligman, M. (1991). Disability and the family: Current status and future developments.

[10] Maholmes, V. (2014). Fostering Resilience and Well-being in Children and Families in Poverty: Why Hope Still Matters. Oxford University Press, USA.

[11] Perczek, R., Carver, C. S., Price, A. A., and Pozo-Kaderman, C. (2000). Coping, mood, and aspects of personality in Spanish translation and evidence of convergence with English versions. Journal of personality Assessment, 74(1), 63-87.

[12] Perlman, J. E. (2008). Caminos esquivos para salir de la pobreza. Movilidad intra e intergeneracional em las favelas de Ro de Janeiro. Salir de la pobreza. Perspectivas interdisciplinares sobre la movilidad social. Boston: Banco Mundial, Mayol Ediciones, 225268.

[13] Rasmussen, H. N., Wrosch, C., Scheier, M. F., and Carver, C. S. (2006). Selfregulation processes and health: the importance of optimism and goal adjustment. Journal of personality, 74(6), 1721-1748.

[14] Reis, P. J., and Alligood, M. R. (2014). Prenatal yoga in late pregnancy and optimism, power, and well-being. Nursing science quarterly, 27(1), 30-36.

[15] Riolli, L., and Savicki, V. (2003). Optimism and coping as moderators of the relationship between chronic stress and burnout. Psychological reports, 92(3), 1215-1226.

[16] Salsman, J. M., Brown, T. L., Brechting, E. H., and Carlson, C. R. (2005). The link between religion and spirituality and psychological adjustment: The mediating role of optimism and social support. Personality and social psychology bulletin, 31(4), 522-535.

[17] Scheier, M. F., and Carver, C. S. (1985). Optimism, coping, and health: assessment and implications of generalized outcome expectancies. Health psychology, 4(3), 219. 
[18] Scheier, M. F., Carver, C. S., and Bridges, M. W. (1994). Distinguishing optimism from neuroticism (and trait anxiety, self-mastery, and self-esteem): a reevaluation of the Life Orientation Test. Journal of personality and social psychology, 67(6), 1063.

[19] Sulimani-Aidan, Yafit (2016). Future Expectations as a Source of Resilience among Young People Leaving Care. British Journal of Social Work (2016) 0, 117

[20] Wrosch, C., Scheier, M. F., Miller, G. E., Schulz, R., and Carver, C. S. (2003). Adaptive selfregulation of unattainable goals: Goal disengagement, goal reengagement, and subjective well-being. Personality and Social Psychology Bulletin, 29(12), 1494-1508.

[21] Xanthopoulou, D., Bakker, A. B., Demerouti, E., and Schaufeli, W. B. (2009). Reciprocal relationships between job resources, personal resources, and work engagement. Journal of Vocational behavior, 74(3), 235-244. 